\title{
Flow Meter and Arduino Based Fuel Gauge for Automotive Vehicles
}

\author{
Raj Patel $^{1}$, Hitesh Pungalia ${ }^{2}$, Saurabh Mahajan ${ }^{3}$ \\ Department of mechanical engineering \\ 1, 2, 3 Pimpri chinchwad college of engineering, University of Pune, Pune
}

\begin{abstract}
Design and implementation of digital fuel gange which measures the accurate level of fuel adding while fuel filling process. Now-a-days all fuel bunks having types of digital displays unit in order to display the value of fuel adding to the vehicle. But we don't know whether they adding accurate value or not. In this paper we have proposed a technique to measure the amount of fuel available in tank during static as well as dynamic condition. This system digitally displays the level of fuel inside the tank by using load sensor, flow meter and vibration sensor and these sensors are interfaced with a development board-arduino. Thus, it is an efficient system to detect the fuel volume in the fuel tank, to get instantaneous reading of fuel volume and to avoid petroleum thefts at the various petrol pumps at the time of filling of tanks.
\end{abstract}

Keywords - digital fuel gauge, load sensor, flow meter, vibration sensor, arduino.

\section{Introduction}

Automobile vehicles use fuel as a basic source of energy. Many technologies, over a period of time have been evolved for proper efficient consumption as well as for predicting and accurately concluding the fuel harnessed at each stage of its use in any system. The amount of fuel is indicated in analog form, which does not give exact idea of amount of fuel present in the tank. Thus it is necessary to give exact level of fuel that may give the exact information to the driver of vehicle about the amount of remaining fuel in the storage tank so that the driver can judge the remaining driving distance. A fuel gauge is a device that measures the amount of fuel still in the vehicle. This type of system can be used to measure the amount of gasoline or some other type of liquid. A fuel gauge can be designed in number of ways and many gauges have several flaws that can make readings less accurate.

The existing fuel level measurement techniques are as follows:

Traditional float type measurement technique

Float work on the simple principle of placing a buoyant object with a specific gravity intermediate between those of the process fluid and the headspace vapor into the tank, then attaching a mechanical device to read out the position( as shown in fig 1). The float sinks to the bottom of the headspace vapor and floats on top of the process fluid. [5]

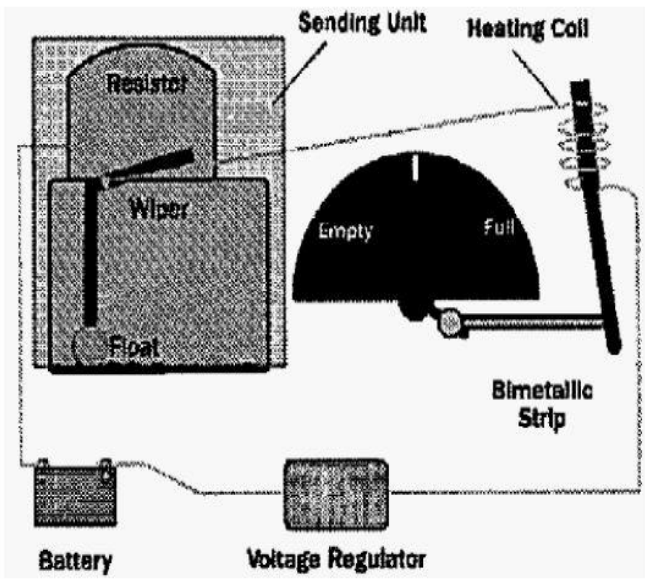

Fig 1: Float type measurement technique.

\section{Capacitance level sensing}

In a capacitance fuel level sensing, the capacitive sensors have two conducting terminal electrodes and the gap between the two rods is fixed the fuel level can be found by measuring the capacitance between the two conductors immersed into the fuel(as shown in fig 2). 


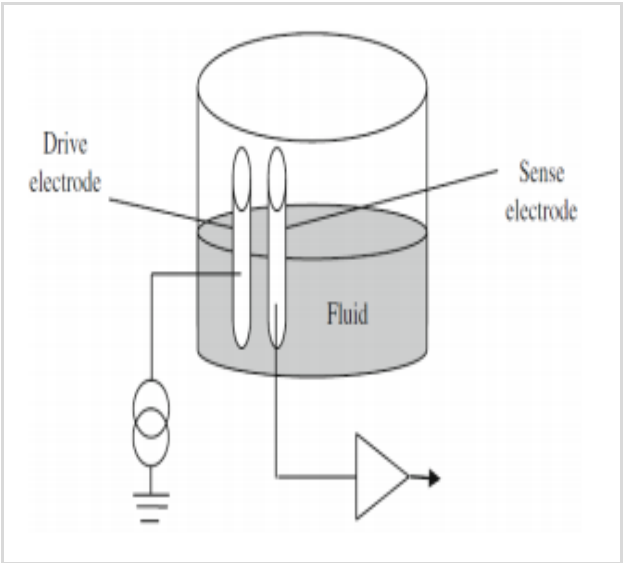

Fig 2: Capacitance level sensing.

Magnetic level sensing

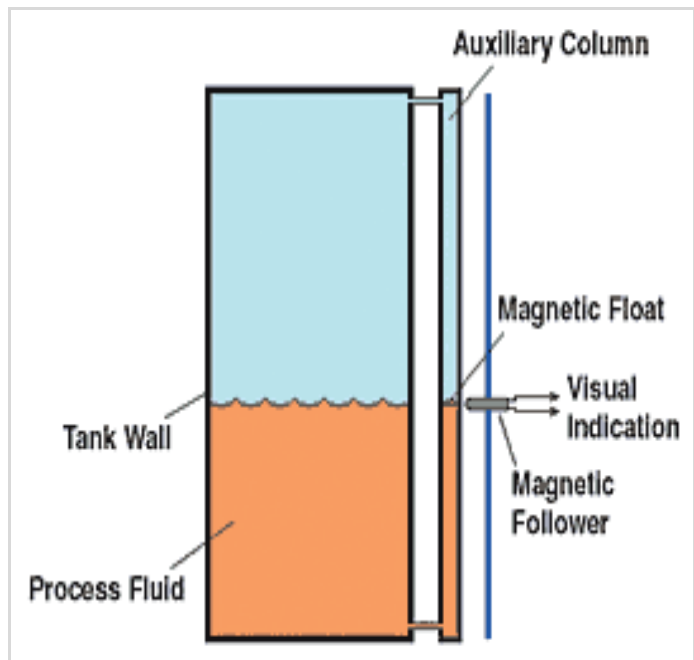

Fig 3: Magnetic level sensing.

The float moves up and down inside the chamber as the liquid level changes. Float type material are determined by the properties of the liquid being measured. The float contains magnet. The transparent external indicator tube contains a magnetized indicator which is coupled with the magnet inside the float. The indicator moves up and down the indicator tube as the float moves up and down with liquid level changes. [6]

\section{Ultrasonic Level Sensing}

The principle of ultrasonic devices is based on the amount of time it takes to send and receive reflected ultrasonic sound wave from the media. [6]

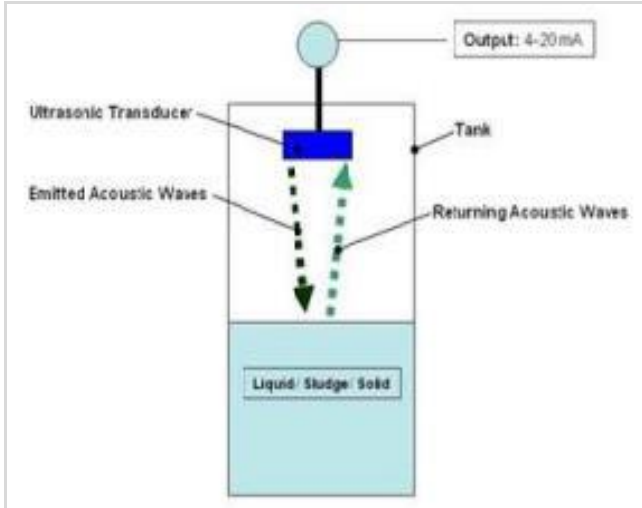

Fig 4: Ultrasonic transmitter. 


\section{Laser level sensing}

A laser transmitter at the top of a vessel fires a short pulse of light down to the process liquid surface, which reflects it back to the detector. A timing circuit measures the elapsed time and calculates the distance. [6]

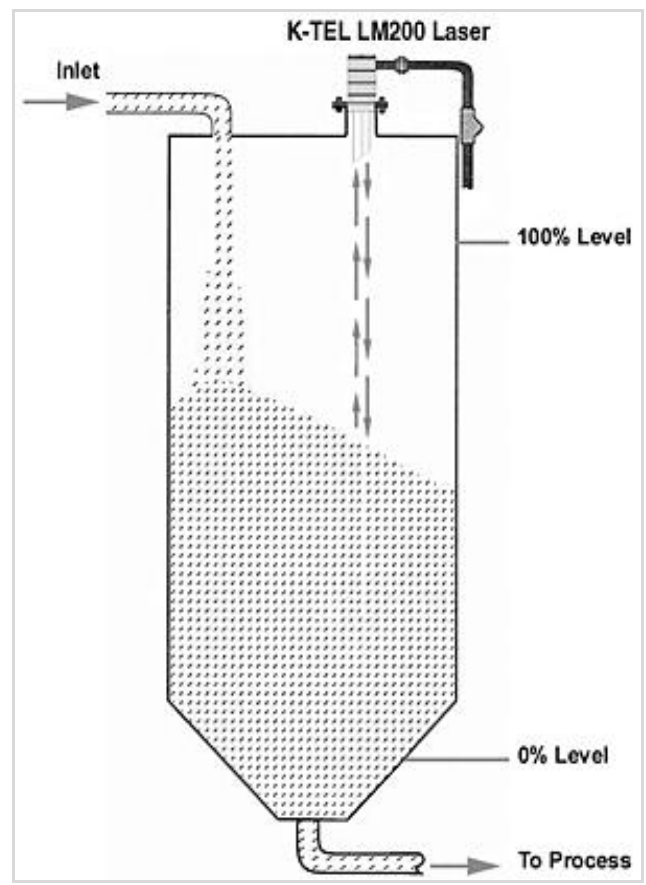

Fig 5: Laser level transmitters.

The demand of sophisticated automated processing system, the need for even-tighter process control, and an increasingly stringent regulatory environment drive process engineers to seek more precise and reliable level measurement system. Improved level measurement accuracy makes it possible to utilize the fuel consumption effectively and minimize the fuel wastage. Automation proposed for any mechanical system requires accuracy, reliability and data analysis. This project work proposes a measurement technology that desires the help meet these requirements.

In 2014 Nitin Jade, Pranjal Shrimali, Asvin Patel and Sagar Gupta developed "modified type intelligent digital fuel indicator system" and achieved an accuracy level of 95\% - 98\% in measuring the fuel digitally [1].

In January 2014 Vinay Divakar developed "Fuel gauge sensing technologies for automotive applications" and achieved a smart fuel gauge system [2].

In April 2013 Jaimon chacko Varghese and Binesh Ellupurayil Balchandran developed "Low cost intelligent real time fuel mileage indicator for motorbikes" and measured the probable distance that can be travelled by the vehicle corresponding to the amount of fuel in the fuel tank can also be estimated [3].

In 2012 Deep Gupta, Brajesh Kr. Singh and Kuldeep Panwar of H.M.R. institute of technology and management developed "A prototyping model for fuel level detector and optimizer" and achieved the measurement of fuel so the accuracy level was $96.36 \%$ - 98\% [4].

\section{Methodology}

In this project, we have designed a fuel measurement system and method that can determine the fuel level in the vehicle tank even when the fuel is sloshing, splashing or experiencing any other dynamic condition. During dynamic conditions, such as when the vehicle is experiencing significant acceleration, manoeuvring, inclination, yaw rate, etc fuel flow sensors are used to determine the amount of fuel consumed, and then subtract that amount from a previous fuel level reading.

The system comprises of three sensors- load cell, flow meter and vibration sensor. Load cell is used in static condition that is when vehicle is at rest and flow meter is used under dynamic condition that is when vehicle is in motion. We are simulating dynamic condition by using a cube vibrating machine. The role of vibration sensor is to sense whether the dynamic condition exists or not. These sensors are interfaced with a development board known as arduino UNO 300. This is a microprocessor which collects data from the above three sensors and processes it according to the program written in C-language. 


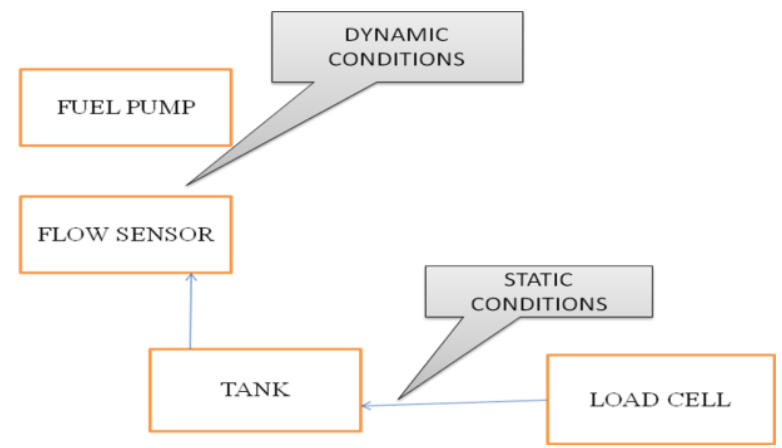

Fig 6: Basic flow chart

For sucking the diesel from tank, we have used pipes and an electronic fuel pump of constant flow rate. Now in static condition the load cell will measure the weight of the diesel present in the tank, this weight measured is divided by the density of diesel to get the volume present in liters. Now as soon as vibration are transmitted to our tank, the vibration sensor will activate a relay switch which turns ON the pump, the pump will suck the diesel from the tank and flow meter is placed in between the tank and pump and hence it will measure the flow rate of diesel instantaneously. Now that data is provided to arduino, now the readings from flow meter is subtracted from the reading obtained from load cell instantaneously which will give the instantaneous volume and will be displayed on the LCD.

\section{Electronic fuel pump}

\section{Theoretical Aspects of Components}

This type of pump (AC UES) was first introduced in 1981 as a diesel transfer pump. The AC UES pump has few moving parts, which do not wear out. It can operate at high temperatures, is quiet, and reliable.[8]

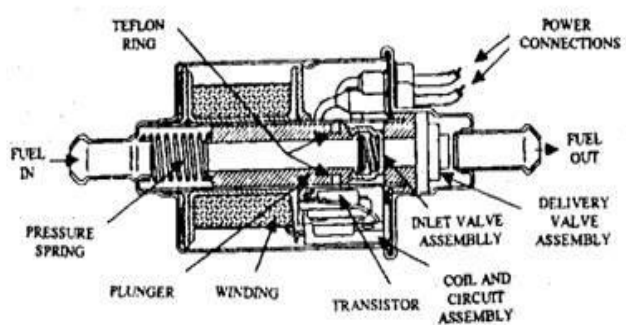

Fig 7: Structure of electronic fuel pump.

\subsection{Fuel Pump Specifications:}

Current: $1.2 \mathrm{~A}$

Flow: $70 \mathrm{~L} / \mathrm{h}$

Input Voltage: $12 \mathrm{~V}$

Output pressure: $3-6 \mathrm{psi}$

Inlet \& Outlet diameter: $8 \mathrm{~mm}$

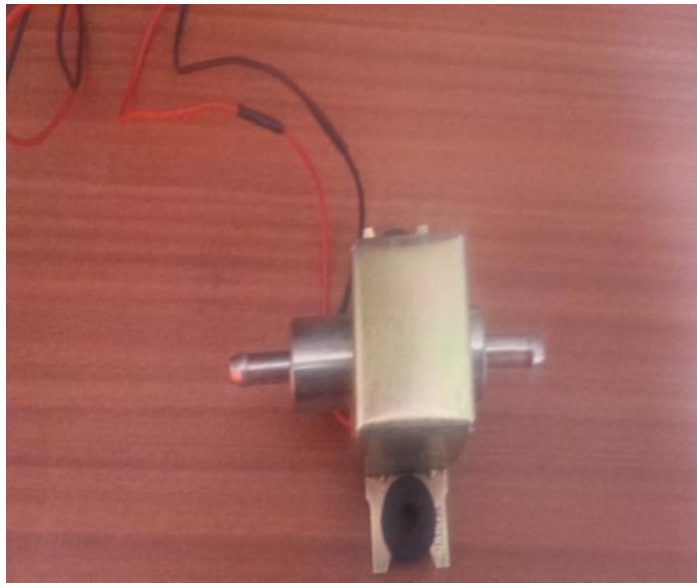

Fig 8: Electronic fuel pump. 


\section{Load cell}

Load Cell is transducer, a device that converts force into electrical signal. The main function of load cell is to convert force into a measurable output, means the load cell allows us to weigh items accurately.

There are basically three types of load cell namely

1. Hydraulic load cell.

2. Pneumatic load cell.

3. Strain gauge load cell.

\section{Flow meters}

The instrument used to measure flow is termed as flow meters. Flow measurement is the quantification of bulk fluid movement. Flow can be measured in a variety of ways. Positive-displacement flow meters accumulate a fixed volume of fluid and then count the number of times the volume is filled to measure flow. Other flow measurement methods rely on forces produced by the flowing stream as it overcomes a known constriction, to indirectly calculate flow. The flow meter used in the project is turbine type flow meter.

\subsection{Flow meter specifications}

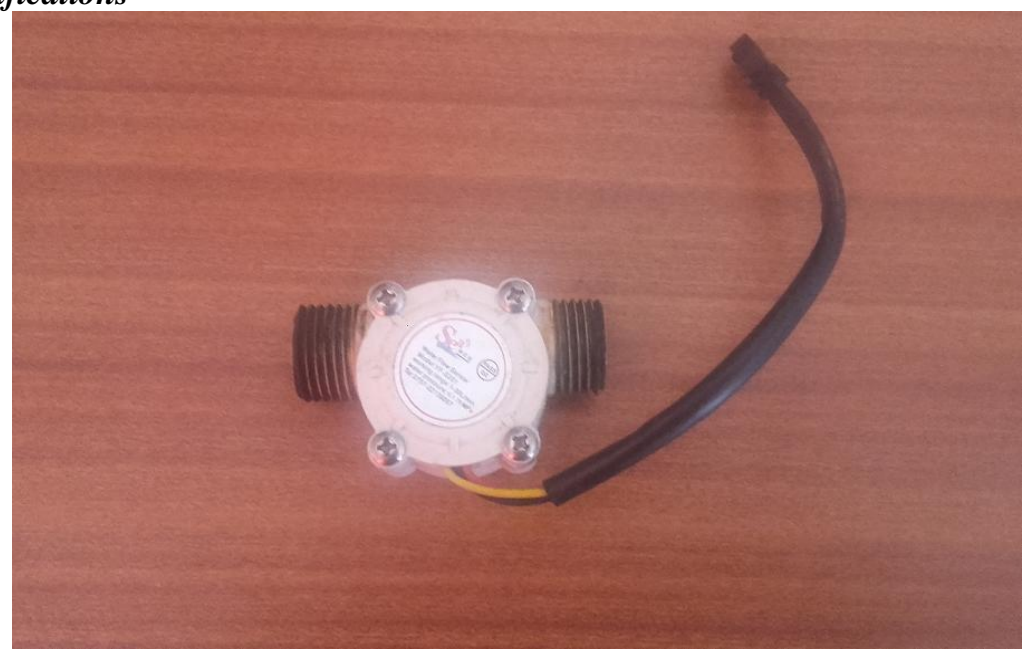

Fig 9: Turbine type flow meter

Type: Turbine type

Working Voltage: 5 to $18 \mathrm{~V}$ DC (min tested working voltage $4.5 \mathrm{~V}$ )

Max current draw: 15mA @ 5V

Output Type: 5V TTL

Working Flow Rate: 1 to 30 Liters/Minute

Working Temperature range: -25 to +80 degree celsius

Maximum water pressure: $2.0 \mathrm{MPa}$

Durability: minimum 300,000 cycles

Cable length: $15 \mathrm{~cm}$

$1 / 2$ " nominal pipe connections, 0.78 " outer diameter, $1 / 2$ " of thread.

\section{Arduino UNO 300}

The Arduino Uno is a microcontroller board based on the ATmega328. It has 14 digital input/output pins (of which 6 can be used as PWM outputs), 6 analog inputs, a $16 \mathrm{MHz}$ crystal oscillator, a USB connection, a power jack, an ICSP header, and a reset button. It contains everything needed to support the microcontroller; simply connect it to a computer with a USB cable or power it with a AC-to-DC adapter or battery to get started.

\section{16x2 LCD display}

LCD (Liquid Crystal Display) screen is an electronic display module and find a wide range of applications. A $16 \times 2$ LCD display is very basic module and is very commonly used in various devices and circuits. A 16x2 LCD means it can display 16 characters per line and there are 2 such lines. In this LCD each character is displayed in $5 \times 7$ pixel matrix. 


\section{Main circuit diagram}

\section{Circuit Diagram}

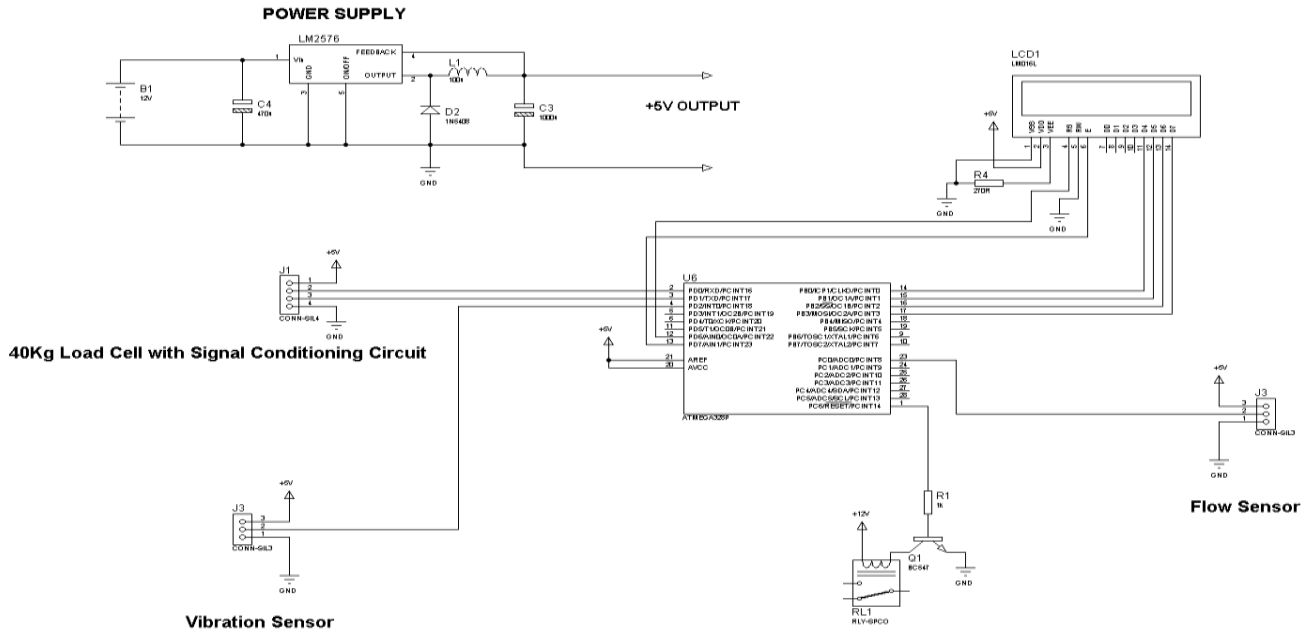

Fig 10: Main circuit diagram

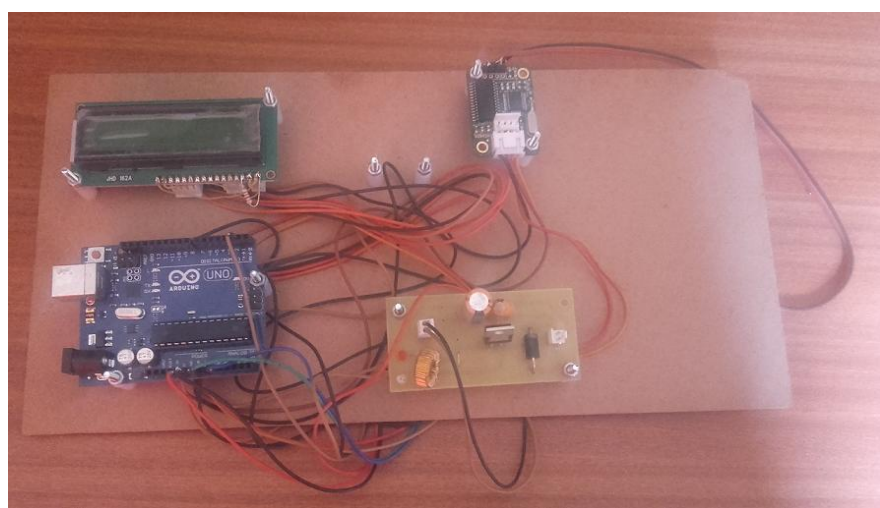

Fig 11: Main circuit

\section{Interfacing load cell with arduino UNO}

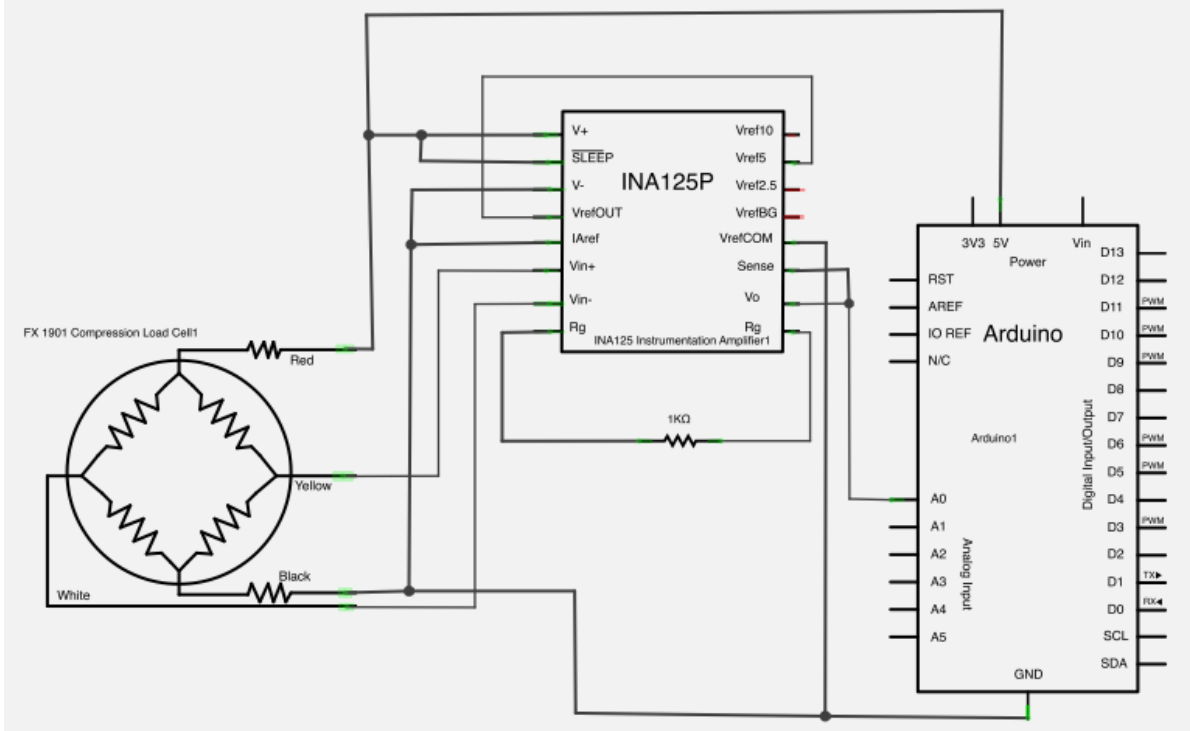

Fig 12: Interfacing load cell with arduino UNO 


\section{Interfacing flow meter with arduino UNO}

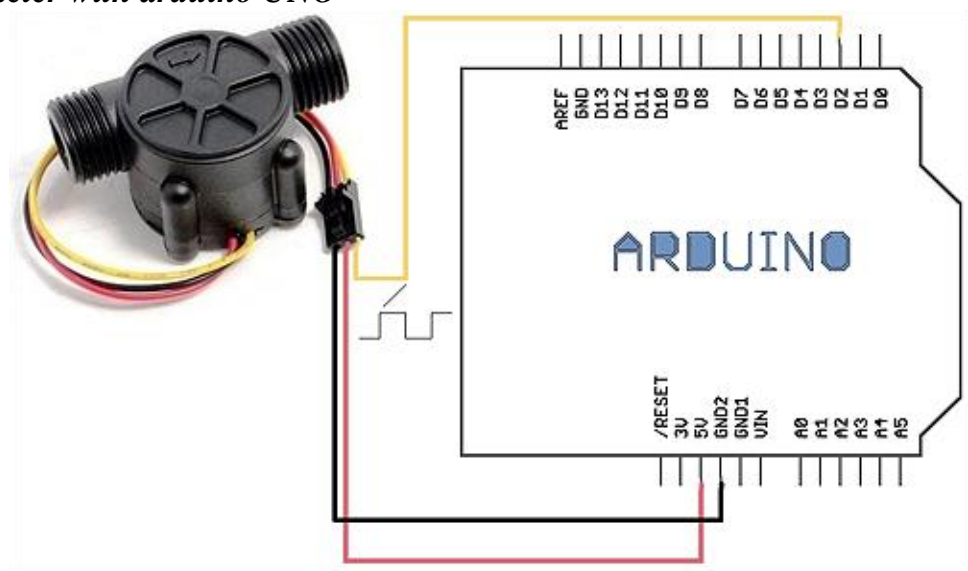

Fig 13: Interfacing flow meter with arduino UNO

\section{Interfacing $L C D$ with arduino $U N O$}

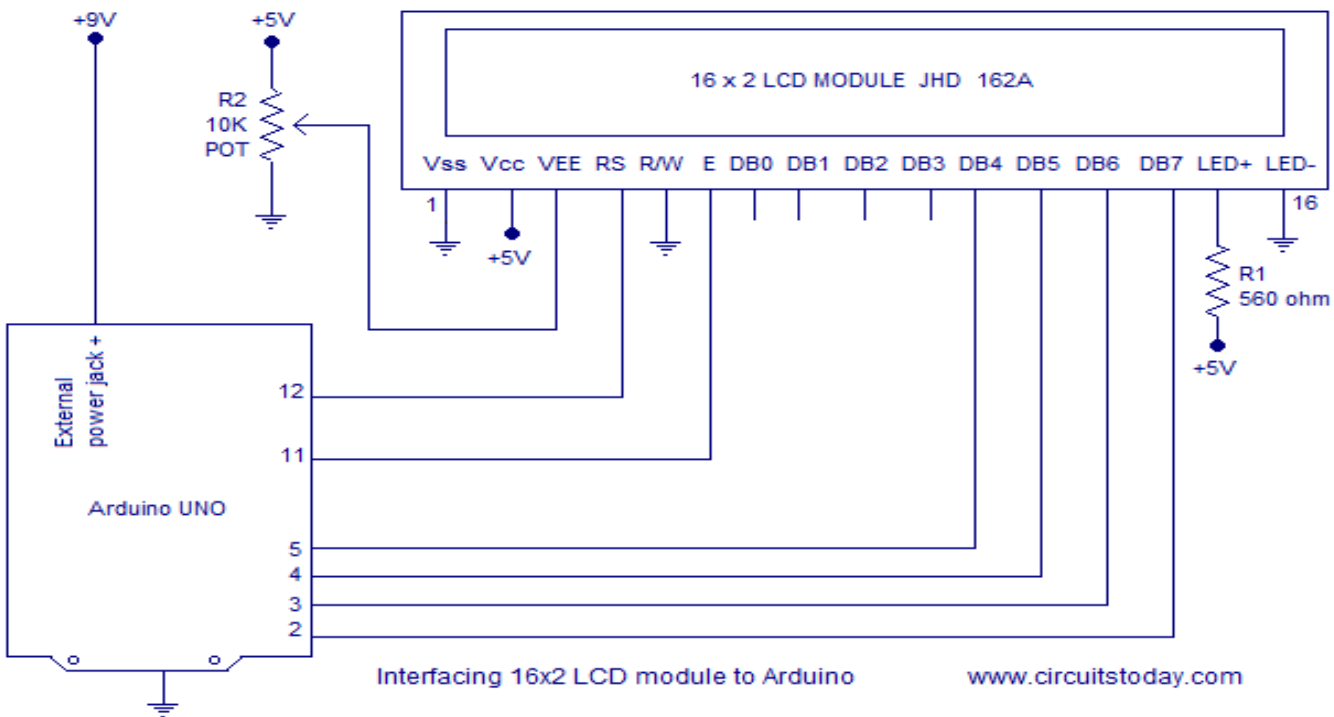

Fig 14: Interfacing LCD with arduino UNO

\section{Validation}

Validation is basically checking the accuracy of our system. The sensors are interfaced with arduino UNO board in order to get the volume in liters. At the end of our setup we have placed a small tank of rectangular cross-section having dimensions LxBxH: 300x200x250. Validation is done by measuring the fuel pumped into the rectangular tank by first measuring the height up to which the tank is filled, then multiplying that height with the cross-sectional area of the tank to get the volume of the diesel being pumped into it.

\begin{tabular}{|l|l|l|}
\hline Readings from load cell(L) & Readings from flow meter $(\mathbf{L})$ & Height of the fuel filled in tank $(\mathbf{m m})$ \\
\hline 1.5 & 1.47 & 24.2 \\
\hline 2 & 1.93 & 30.8 \\
\hline 2.5 & 2.41 & 39.5 \\
\hline 3 & 2.95 & 48.5 \\
\hline 4 & 3.7 & 53.3 \\
\hline
\end{tabular}

Table 1: Validation table

\section{Sample Calculations:}

\section{For 1st observations:}

Height measured (h)

$=24.2 \mathrm{~mm}=0.0242 \mathrm{~m}$

Cross-sectional area of the rectangular tank $(\mathrm{A})=0.06 \mathrm{~m}^{2}$

Therefore, volume of the tank filled $(\mathrm{V}) \quad=\mathrm{hxA}$

$$
=(0.0242 \times 0.06) / 1000
$$

$=1.452 \mathrm{~L}$ 


\section{Results}

From the validation it seems there is some error in the readings of sensors as well as in the readings of height of the fuel tank. The error shown by the sensors is because some amount of diesel always remains in the pipeline which tends to show different reading of flow meter than load cell and because of human error while measuring the height of the fuel filled in the tank may cause some difference in the results.

\section{Conclusion}

Many industries have found been interest in measuring the fluid level in the reservoir at various considerations. In this project work, an attempt is made to design and develop an experimental set up to measure the fluid level in the reservoir.

We have used basically using two circuits. During still condition we have measured fuel volume using weight measuring sensors. During dynamic conditions we have used fuel usage signals from one or more fuel meters to determine the amount of fuel consumed and subtracting that amount from the previous reading.

\section{Future Enhancements}

The proposed project work has aimed for developing a feasible low cost automation technique to measure the fluid level and its quantity. We can achieve least possible error and maximum accuracy in the measurement. We are designing a system which digitally displays the level of liquid inside the tank. Thus it is an efficient device made by keeping in mind the petroleum thefts at the various petrol pumps at the time of filling of tanks.

In future we can also add some features like displaying mileage or distance to go before the tank gets empty.

\section{Journal Papers}

\section{References}

[1]. Nitin jade, Pranjal Shrimali, Asvin Patel and Sagar Gupta, (2014). "Modified type intelligent digital fuel indicator system", IOSRJMCE, e-ISSN: 2278-1684, p-ISSN: 2320-334X

[2]. Vinay Divakar, (2014). "Fuel gauge sensing technologies for automotive applications", IJARCET, volume 3 issue 1, January 2014

[3]. Jaimon Chacko Varghese, Binesh Ellupurayil Balchandran. April 2013. "Low cost intelligent real time fuel mileage indicator for motorbikes", IJITEE, ISSN: 2278-3075, volume-2, issue-5.

[4]. Deep Gupta, Brajesh kr. Singh and Kuldeep Panwar, "A prototyping model for fuel level detector and optimizer", African journal of basic \& applied sciences 4 (6): 226- 229, 2012 ISSN 2079-2034.

\section{Patent}

[5]. US7865317 B2, (United States of America), Jan 4 2011, system and Method for Measuring Fuel Level in Vehicle Fuel Tank.

[6]. US5157968, (United States of America), Oct 27 1992, Apparatus for Measuring Specific Gravity, Weight, Level and/or Volume in

\section{Handbook}

$$
\text { a Container }
$$

[7]. Handbook of transducers, 2014

[8]. Handbook of pumps, 2 